\title{
Luminescence and Raman Spectra of Acetylacetone at Low Temperatures
}

\author{
Vlasta Mohaček-Grošev ${ }^{\mathrm{a}}$, Krešimir Furić ${ }^{\mathrm{a}}$, Hroje Ivankovićc
}

\begin{abstract}
Raman spectra of acetylacetone were recorded for molecules isolated in an argon matrix at $10 \mathrm{~K}$ and for a polycrystalline sample. In the solid sample, broad bands appear superimposed on a much weaker Raman spectrum corresponding mainly to the stable enol form. The position of these bands depends on the excitation wavelength (514.5 and $488.8 \mathrm{~nm}$ argon ion laser lines were used), sample temperature, and cooling history. They are attributed to transitions from an excited electronic state to various isomer states in the ground electronic state. Laser photons have energies comparable to energies of a number of excited triplet states predicted for a free acetylacetone molecule (Chen, X.-B.; Fang, W.-H.; Phillips, D. L. J. Phys. Chem. A 2006, 110, 4434). Since singlet-to-triplet photon absorption transitions are forbidden, states existing in the solid have mixed singlet/triplet character. Their decay results in population of different isomer states, which except for the lowest isomers SYN enol, TS2 enol (described in Matanović I.; Došlić, N. J. Phys. Chem. A 2005, 109, 4185), and the keto form, which can be detected in the Raman spectra of the solid, are not vibrationally resolved. Differential scanning calorimetry detected two signals upon cooling of acetylacetone, one at $229 \mathrm{~K}$ and one at $217 \mathrm{~K}$, while upon heating, they appear at 254 and $225 \mathrm{~K}$. The phase change at higher temperature is attributed to a freezing/melting transition, while the one at lower temperature seems to correspond to freezing/melting of keto domains, as suggested by Johnson et al. (Johnson, M. R.; Jones, N. H.; Geis, A; Horsewill. A. J.; Trommsdorff, H. P. J. Chem. Phys. 2002, 116, 5694). Using matrix isolation in argon, the vibrational spectrum of acetylacetone at $10 \mathrm{~K}$ was recorded. Strong bands at 1602 and $1629 \mathrm{~cm}^{-1}$ are assigned as the SYN enol bands, while a weaker underlying band at $1687 \mathrm{~cm}^{-1}$ and a medium shoulder at $1617 \mathrm{~cm}^{-1}$ are assigned as TS2 enol bands.
\end{abstract}

\section{Introduction}

Acetylacetone (2,4-pentanedione), acac, serves as a model for the study of intramolecular hydrogen bonding, together with other $\beta$ diketone molecules. ${ }^{1}$ It is often used as a complexing agent with various metal ions $s^{2,3}$ and in producing compounds for organic light-emitting diodes. ${ }^{4}$ It is a rather small molecule but of rich dynamics, exhibiting effects of tautomerism. In the simplest model, two molecular species, enol and keto, exist in equilibrium at room temperature in the approximate ratio of 3:1 in favor of the enol. ${ }^{1}$ Temperature $^{\underline{5}}$ and solvents ${ }^{6}$ are known to affect this ratio and move it either toward the enol or keto side.

\footnotetext{
${ }^{a}$ Ruđer Bošković Institute, P.O. Box 180, Bijenička c. 54, 10002 Zagreb, Croatia (mohacek@irb.hr)

${ }^{b}$ Faculty of Chemical Engineering and Technology, Marulićev trg 19, 10000 Zagreb, Croatia
} 
The potential energy surface that determines the positions of the tautomeric minima has been intensively studied ${ }^{7-18}$ Matanović et al. explored the potential energy surface for proton transfer in acetylacetone. ${ }^{12}$ The ground state was found to be SYN enol (see Figure 1). The transition state TS2 was only $0.25 \mathrm{kcal} / \mathrm{mol}$ higher in energy than SYN enol, and the transition state TS1 had an energy that was $1.45 \mathrm{kcal} / \mathrm{mol}$ higher than that of SYN. The main difference in geometry between the TS1 and TS2 transition states concerns the orientation of the methyl groups (Figure 1). Although the SYN, TS1, and TS2 conformers have $C_{s}$ symmetry, the experimental difficulties in detecting the position of the hydroxyl proton raise the possibility of identifying unrelaxed molecules in the TS1 and TS2 states and reporting them as molecules having $C_{2 v}$ symmetry because the methyl groups are placed symmetrically with respect to the plane containing oxygen atoms in both TS1 and TS2. Thus, the X-ray diffraction experiment conducted at 210 and $110 \mathrm{~K}$ by Boese et al. ${ }^{19}$ reported acetylacetone molecules with $C_{2 v}$ symmetry. Johnson et al. ${ }^{20}$ measured methyl tunneling splitting energies in polycrystalline acac using the quasielastic neutron scattering diffraction technique. They showed that rapid cooling of liquid acac results in a polycrystalline mixture of enolic and keto tautomers and succeeded in producing pure enolic polycrystalline powder. The method used was to anneal the sample below the melting point (at $245 \mathrm{~K}$ ) for $10 \mathrm{~h}$. The two different methyl tunneling splitting energies that were measured for the annealed sample at $5 \mathrm{~K}$ were assigned as originating from two different methyl groups of the same molecule. Their work supports the SYN enol form as the stable enolic form of acetylacetone in the crystal state.

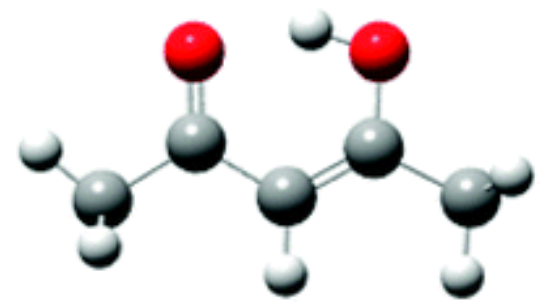

SYN enol

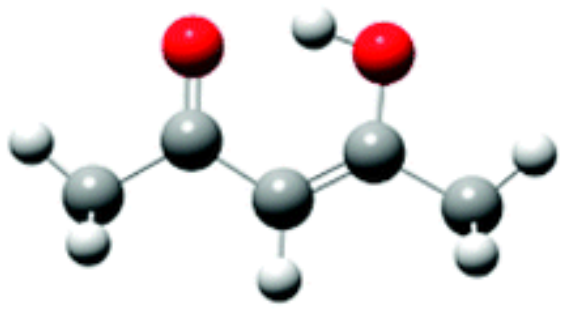

TS1 enol

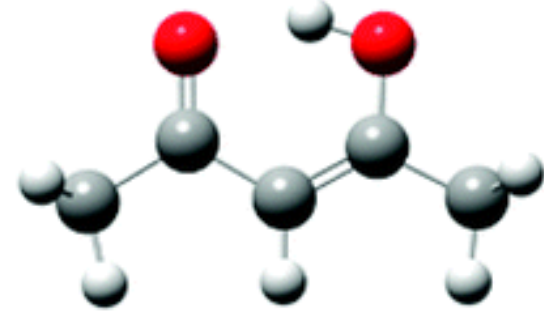

TS2 enol

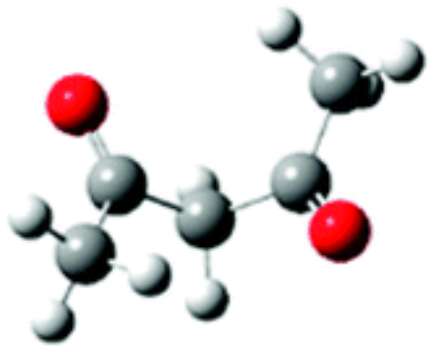

keto

Fig 1 Figure 1 Enol (SYN, TS2, and TS1) and keto tautomers of acetylacetone. The SYN enol is the most stable configuration, and TS2 and TS1 are transition states 0.25 and $1.45 \mathrm{kcal} / \mathrm{mol}$ higher in energy than SYN, respectively. ${ }^{10}$ 
For the free acac molecule, experiments involved in determination of the minimum energy conformation include high-resolution rotational spectra of Caminatti and Grabow ${ }^{21}$ and electron diffraction experiments by Lowrey et al., ${ }^{22}$ which were in favor of the $C_{2 v}$ equilibrium structure. On the contrary, electron diffraction experiments by Ijima et al..$^{23}$ and Srinivasan et al. $\frac{24}{}$ argued that the planar but nonsymmetrical $C_{s}$ structure was the most stable. Camerman et al. identified enolic acetylacetone as residual solvent in a crystal of antiepileptic drugs. $\frac{25}{.}$ After the discovery of Veierov et al. $\frac{26}{}$ that acetylacetone displays isomerization upon UV illumination, a number of studies were devoted to isolation of different isomers and calculation of their relative energies. $\frac{27-34}{}$

Vibrational studies of acetylacetone gave a thorough assignment of bands for the enolic $C_{s}$ tautomer, and some, more intense, bands of the keto tautomer could be confidently attributed. $\cdot 35-$ ${ }^{39}$ Tayyari $^{35}$ reported the SYN conformer as the most stable form (his notation I), which coexists in liquid with TS2 (II in his notation). He assigned the low-temperature $1635 \mathrm{~cm}^{-1}$ band to the stable conformer and the $1600 \mathrm{~cm}^{-1}$ low-temperature band to the conformer II (TS2). Chiavassa et al. first performed infrared matrix-isolation experiments, ${ }^{36}$ and later Coussan et al. included induced UV and IR isomerizations of matrix-isolated acac. ${ }^{29}$

We undertook the Raman matrix-isolation experiment to verify the conclusion of Cohen and Weiss ${ }^{5}$ and Tayyari ${ }^{35}$ that there exists two enolic forms rapidly interconverting in the liquid. Also, low-temperature Raman spectra of the polycrystalline sample were collected from 10 to $300 \mathrm{~K}$ for the study of the possible disorder of the methyl groups.

\section{Experimental Methods}

Acetylacetone (acac), 99.5\% pure, was purchased from Sigma-Aldrich (Fluka) and transferred to a capillary tube with several freeze-pump-thaw cycles performed to eliminate dissolved air. The capillary was sealed under vacuum. For low-temperature measurements, we used several cryostats, an old CTI model 21 CRYOGENICS, a new CCS350 JANIS RESEARCH, both with a closed cycle of liquid helium, which could reach $10 \mathrm{~K}$, and a VPF 700 from JANIS RESEARCH, operating with liquid nitrogen for temperatures as low as $80 \mathrm{~K}$. For temperature control, a Lake Shore 331 instrument was used.

For the matrix-isolation experiment, a small amount of pure liquid acac was transferred into glass vial, and freeze-pump-thaw cycles were repeated. The vial with frozen sample was evacuated with rotary and diffusion pumps and then connected to a Swagelok needle valve leading to the cold golden-plated cryostat finger on one side and to the reservoir of argon on the other. The vapor pressure of liquid acac is $0.8 \mathrm{kPa}$ (from the Sigma-Aldrich website). After the sample melted at room temperature, acac vapor was allowed to mix with argon from the reservoir held at a pressure of $1 \mathrm{~atm}$ by opening the valve toward argon. The matrix ratio was estimated from the ratio of pressures of acetylacetone vapor and argon and was approximately 1:100. The vapor/gas mixture was deposited on the golden surface inside of the cryostat head 
cooled to $10 \mathrm{~K}$. Traces of air were found $\left(2328 \mathrm{~cm}^{-1}\right.$ from the $\mathrm{N}_{2}$ stretching band and $1554 \mathrm{~cm}^{-1}$ from the $\mathrm{O}_{2}$ stretching band) because of imperfect sealing.

A differential scanning calorimetry experiment was performed with Netzsch DSC 200 instrument equipped with a liquid nitrogen cooling system in a He atmosphere. The cooling rate was $5 \mathrm{~K} / \mathrm{min}$, and the heating rate was also $5 \mathrm{~K} / \mathrm{min}$.

Raman spectra were recorded with the DILOR Z24 Raman spectrometer, while excitation was provided with an argon ion laser (COHERENT INNOVA 400) operating at 514.5 and $488.8 \mathrm{~nm}$ with a laser power of $200 \mathrm{~mW}$ at the sample. Spectra were recorded in the sequential mode, and the step sizes used ranged from 0.5 to $4 \mathrm{~cm}^{-1}$. The slit width was $300 \mu \mathrm{m}$, giving spectral resolution of $2.3 \mathrm{~cm}^{-1}$.

\section{Results}

Matrix-Isolation Experiment. Infrared and Raman spectra of liquid acac are shown in Figure 2, and Raman spectrum of the matrix-isolated sample is shown in Figure 3. The positions of selected observed bands are listed in Table 1, while the complete list is given in the Supporting Material. The assignment of the enol bands was done according to the calculation by Matanovic and Došlić, ${ }^{7}$ and the keto bands attributed according to our calculation performed at the B3LYP/6-311++G(d, p) level of theory. ${ }^{40}$ The calculated unscaled values for the keto tautomer are listed in Table 2 of the Supporting Material. Several keto bands in liquid could be confidently identified by comparing the spectra of polycrystalline acac containing only enol molecules and the liquid spectra; the $1730 \mathrm{~cm}^{-1}$ band was attributed to $\mathrm{C}=\mathrm{O}$ groups stretching out of phase, the $1709 \mathrm{~cm}^{-1}$ band was attributed to $\mathrm{C}=\mathrm{O}$ groups stretching in phase, the $1157 \mathrm{~cm}^{-1}$ band corresponded to the $\delta\left(\mathrm{CH}_{2}\right)$, the $957 \mathrm{~cm}^{-1}$ band corresponded to skeletal $\mathrm{C}-\mathrm{C}$ stretching, the 621

$\mathrm{cm}^{-1}$ band was assigned to $\mathrm{C}-\mathrm{CH}_{2}-\mathrm{C}$ bending, and the $330 \mathrm{~cm}^{-1}$ band was assigned to $\mathrm{H}_{3} \mathrm{C}-\mathrm{C}-\mathrm{C}$ bending. 
Mohaček-Grošev, V., Furić, K., Ivanković, H. (2007), "Luminescence and Raman Spectra of Acetylacetone at Low Temperatures", Journal of Physical Chemistry. A, Vol. 111, No. 26, pp. 5820-5827.
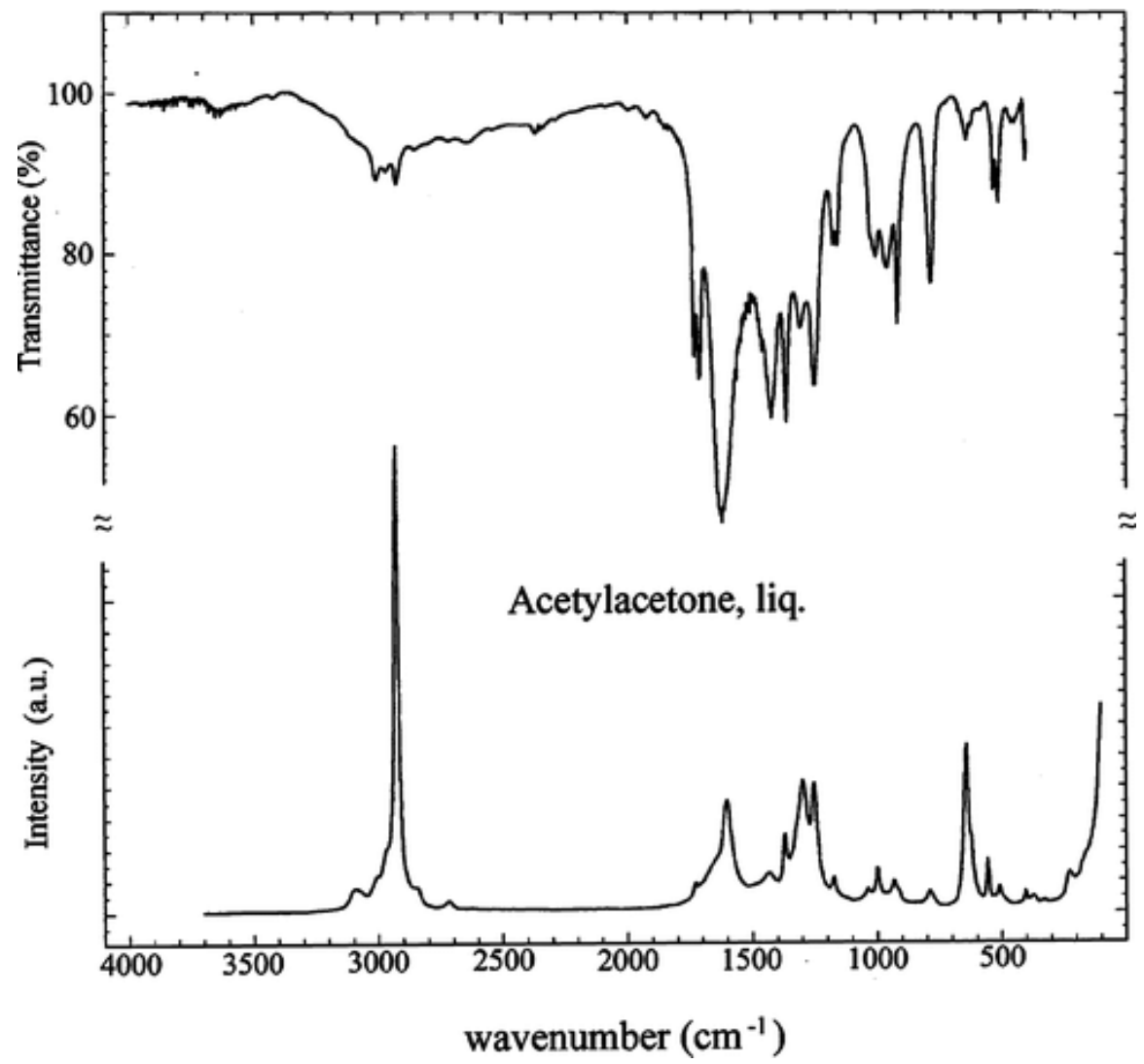

Fig 2 Infrared and Raman spectra of liquid acetylacetone.

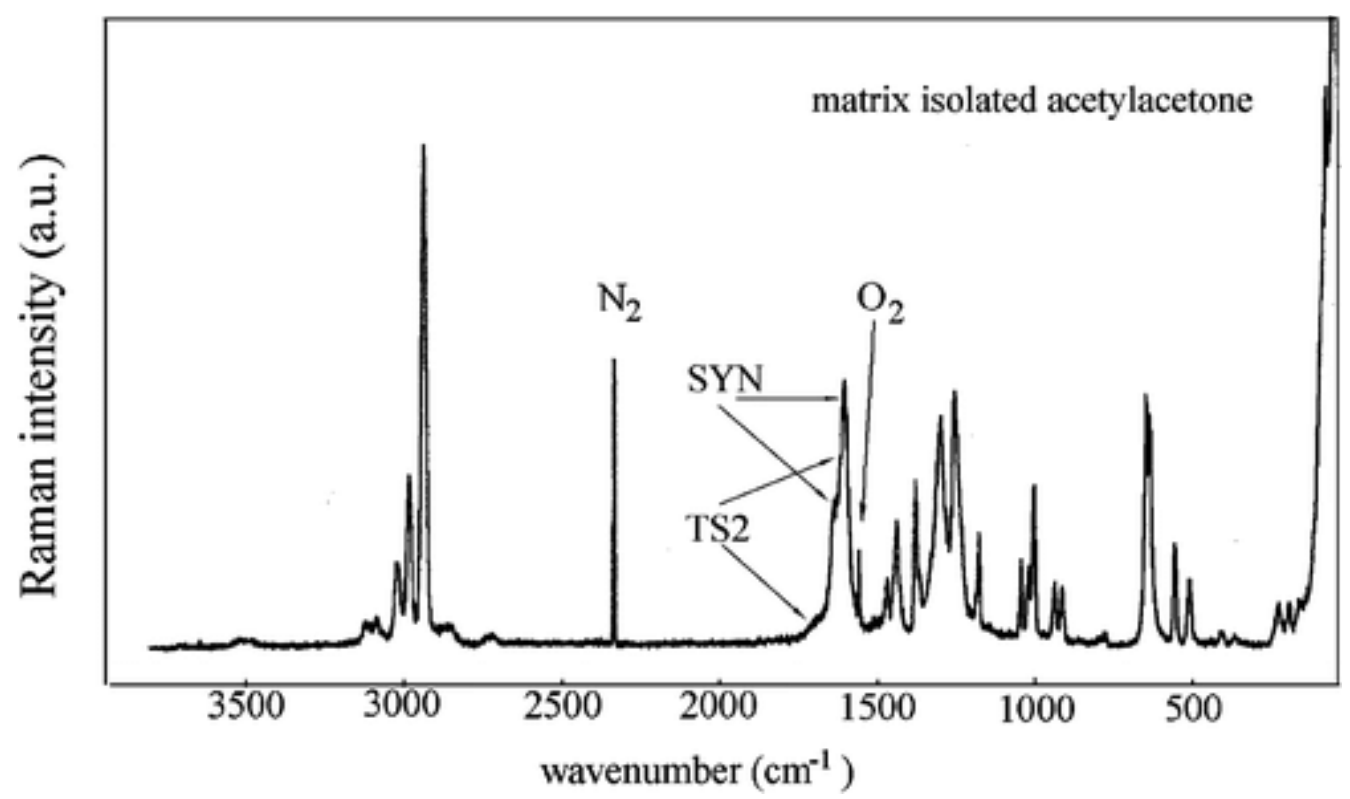

Fig 3 Raman spectrum of acetylacetone isolated in an argon matrix at $10 \mathrm{~K}\left(10-3800 \mathrm{~cm}^{-1}\right)$. The matrix ratio is $\sim 1: 100$. 
Mohaček-Grošev, V., Furić, K., Ivanković, H. (2007), "Luminescence and Raman Spectra of Acetylacetone at Low Temperatures", Journal of Physical Chemistry. A, Vol. 111, No. 26, pp.

5820-5827.

Table 1 Selected Observed Raman and Infrared Bands of Acetylacetone $\left(\mathrm{cm}^{-1}\right)^{a, b}$

\begin{tabular}{|c|c|c|c|c|c|c|}
\hline $\begin{array}{l}\text { Raman matrix } \\
10 \mathrm{~K}\end{array}$ & $\begin{array}{l}\text { Raman solid } 10 \mathrm{~K} \\
\text { enols + keto }\end{array}$ & $\begin{array}{l}\text { Raman solid } \\
10 \mathrm{~K} \\
\text { enols }+ \text { keto }\end{array}$ & $\begin{array}{l}\text { Raman solid } \\
10 \mathrm{~K} \text { enols }\end{array}$ & $\begin{array}{l}\text { Raman liquid } \\
295 \mathrm{~K} \\
\text { enols + keto }\end{array}$ & $\begin{array}{l}\text { infrared liquid } \\
295 \mathrm{~K} \\
\text { enols }+ \text { keto }\end{array}$ & assignment \\
\hline & $1800 \mathrm{~m}, \mathrm{vbr}$ & & & & & luminescent band \\
\hline & $1715 \mathrm{w}$ & $1715 \mathrm{vvw}$ & & $1732 \mathrm{w}$ & $1730 \mathrm{~s}$ & $v(\mathrm{C}=\mathrm{O})$ keto, out-of-phase \\
\hline & $1700 \mathrm{w}$ & $1698 \mathrm{vVw}$ & & & $1709 \mathrm{~s}$ & $v(\mathrm{C}=\mathrm{O})$ keto, in-phase \\
\hline \multirow[t]{3}{*}{$1687 \mathrm{w}, \mathrm{sh}$} & & & $1683 \mathrm{w}$ & & & $v(\mathrm{C}=\mathrm{C}-\mathrm{C}=\mathrm{O}) \mathrm{TS} 2 \mathrm{enol}$ \\
\hline & & & & $1672 \mathrm{br},=\mathrm{sh}$ & & \\
\hline & $1651 \mathrm{mw}, \mathrm{sh}$ & $1653 \mathrm{mw}, \mathrm{sh}$ & $1652 \mathrm{mw}, \mathrm{sh}$ & & & $\begin{array}{l}v(\mathrm{C}=\mathrm{C}-\mathrm{C}=\mathrm{O}) \mathrm{SYN} \text { enol, } \\
\text { crystal spliting }\end{array}$ \\
\hline $1629 \mathrm{~m}, \mathrm{sh}$ & $1634 \mathrm{~m}$ & $1638 \mathrm{mw}$ & $1634 \mathrm{~ms}$ & & $1622 \mathrm{vs}, \mathrm{vbr}$ & $v(\mathrm{C}=\mathrm{C}-\mathrm{C}=\mathrm{O}) \mathrm{SYN}$ enol \\
\hline $1617 \mathrm{~m}, \mathrm{sh}$ & & & & & & $v(\mathrm{C}=\mathrm{O})+\delta(\mathrm{O}-\mathrm{H}) \mathrm{TS} 2 \mathrm{enol}$ \\
\hline \multirow[t]{5}{*}{$1602 \mathrm{~s}$} & $1605 \mathrm{~m}$ & $1605 \mathrm{~m}$ & $1607 \mathrm{~ms}$ & $1604 \mathrm{~s}, \mathrm{br}$ & & $v(\mathrm{C}=\mathrm{O})+\delta(\mathrm{O}-\mathrm{H}) \mathrm{SYN}$ enol \\
\hline & $1585 \mathrm{mw}, \mathrm{sh}$ & $1583 \mathrm{mw}$ & $1585 \mathrm{~m}$ & & & $\begin{array}{l}v(\mathrm{C}=\mathrm{O})+\delta(\mathrm{O}-\mathrm{H}) \mathrm{SYN} \text { enol, } \\
\text { crystal splitting }\end{array}$ \\
\hline & $1355 \mathrm{w}, \mathrm{sh}$ & $1354 \mathrm{w}$ & $1355 \mathrm{w}$ & & & $\delta(\mathrm{O}-\mathrm{H})+v(\mathrm{C}=\mathrm{O}) \mathrm{SYN}$ enol \\
\hline & $1309 \mathrm{mw}, \mathrm{sh}$ & $1310 \mathrm{w}, \mathrm{sh}$ & $1308 \mathrm{w}, \mathrm{sh}$ & & & $v(\mathrm{C}-\mathrm{C}=\mathrm{C})+\delta(\mathrm{OH}) \mathrm{SYN}$ enol \\
\hline & & & $1300 \mathrm{~s}, \mathrm{vbr}$ & & & luminescent band \\
\hline $1296 \mathrm{~s}$ & $1296 \mathrm{~m}, \mathrm{br}$ & $1297 \mathrm{mw}, \mathrm{br}$ & $1298 \mathrm{~ms}$ & $1296 \mathrm{~s}, \mathrm{br}$ & $1307 \mathrm{~ms}$ & $\begin{array}{l}v(\mathrm{C}-\mathrm{C}=\mathrm{C})+\delta(\mathrm{O}-\mathrm{H}) \mathrm{SYN} \text { enol, } \\
\text { crystal splitting }\end{array}$ \\
\hline $1200 \mathrm{w}, \mathrm{br}$ & & & & & & $\delta(\mathrm{CH})$ in-plane bending TS2 enol \\
\hline \multirow[t]{2}{*}{$1175 \mathrm{~m}$} & $1173 \mathrm{mw}$ & $1174 \mathrm{~m}$ & $1173 \mathrm{~m}$ & $1176 \mathrm{mw}$ & $1172 \mathrm{~m}$ & $\delta(\mathrm{CH})$ in-plane bending SYN enol \\
\hline & & & & & $1157 \mathrm{~m}$ & $\delta\left(\mathrm{CH}_{2}\right)$ keto \\
\hline $647 \mathrm{~s}$ & $648 \mathrm{~s}$ & $648 \mathrm{~ms}$ & $649 \mathrm{~s}$ & & $643 \mathrm{mw}$ & out-of-plane ring bend SYN enol \\
\hline \multirow[t]{2}{*}{$635 \mathrm{~s}$} & $642 \mathrm{~s}$ & $642 \mathrm{~ms}$ & $643 \mathrm{~s}$ & $645 \mathrm{~s}$ & & in-plane ring def. SYN enol \\
\hline & $624 \mathrm{mw}$ & & & $623 \mathrm{~ms}, \mathrm{sh}$ & $621 \mathrm{mw}, \mathrm{sh}$ & $\mathrm{C}-\mathrm{CH}_{2}-\mathrm{C}$ bending, keto tautomer \\
\hline $615 \mathrm{w}, \mathrm{sh}$ & & & & & $583 \mathrm{w}$ & in-plane ring def. TS2 enol \\
\hline \multirow[t]{2}{*}{$555 \mathrm{mw}$} & $555 \mathrm{~ms}$ & $554 \mathrm{~m}$ & $554 \mathrm{~ms}$ & $556 \mathrm{~m}$ & & out-of-plane ring def. SYN enol \\
\hline & $534 \mathrm{vw}$ & & & $530 \mathrm{vw}$ & $531 \mathrm{mw}$ & $\begin{array}{l}\mathrm{C}=\mathrm{O} \text { in-plane bending, out-of- } \\
\text { phase, keto tautomer }\end{array}$ \\
\hline \multirow[t]{2}{*}{$509 \mathrm{w}$} & $504 \mathrm{~m}$ & $505 \mathrm{mw}$ & $504 \mathrm{~m}$ & $510 \mathrm{vw}$ & $513 \mathrm{mw}$ & in-plane ring bend SYN enol \\
\hline & $413 \mathrm{w}$ & $413 \mathrm{w}$ & $412 \mathrm{w}$ & & & in-plane ring def. SYN enol \\
\hline $406 \mathrm{vw}$ & $404 \mathrm{w}$ & $406 \mathrm{vw}$ & $403 \mathrm{w}$ & $406 \mathrm{w}$ & & in-plane ring def. TS2 enol \\
\hline \multirow[t]{3}{*}{$365 \mathrm{vw}$} & $358 \mathrm{w}, \mathrm{br}$ & $353 \mathrm{w}$ & $355 \mathrm{w}, \mathrm{br}$ & $372 \mathrm{w}$ & & in-plane ring def. SYN enol \\
\hline & $340 \mathrm{w}, \mathrm{sh}$ & & & $330 \mathrm{w}$ & & $\mathrm{H}_{3} \mathrm{C}-\mathrm{C}-\mathrm{C}$ bending, keto tautomer \\
\hline & $235 \mathrm{mw}$ & $234 \mathrm{mw}$ & $236 \mathrm{mw}$ & & & $\begin{array}{l}\text { out-of-plane ring bend }+\gamma\left(\mathrm{C}-\mathrm{CH}_{3}\right) \\
\text { crystal splitting SYN enol }\end{array}$ \\
\hline \multirow[t]{2}{*}{$225 \mathrm{w}$} & & & $226 \mathrm{mw}, \mathrm{sh}$ & $228 \mathrm{mw}$ & & $\begin{array}{l}\text { out-of-plane ring bend }+\gamma\left(\mathrm{C}-\mathrm{CH}_{3}\right) \\
\text { SYN enol }\end{array}$ \\
\hline & & & $203 \mathrm{mw}, \mathrm{sh}$ & & & $\begin{array}{l}\text { out-of-plane ring bend }+\gamma\left(\mathrm{C}-\mathrm{CH}_{3}\right) \\
\text { crystal splitting SYN enol }\end{array}$ \\
\hline $192 \mathrm{w}$ & $198 \mathrm{~m}$ & $196 \mathrm{~ms}$ & $197 \mathrm{~m}$ & & & $\begin{array}{l}\text { out-of-plane ring bend }+\tau\left(\mathrm{CH}_{3}\right) \\
\text { SYN enol }\end{array}$ \\
\hline & $174 \mathrm{w}$ & $170 \mathrm{mw}$ & $174 \mathrm{w}$ & & & out-of-plane ring bend $+\tau\left(\mathrm{CH}_{3}\right)$ \\
\hline
\end{tabular}


Mohaček-Grošev, V., Furić, K., Ivanković, H. (2007), "Luminescence and Raman Spectra of Acetylacetone at Low Temperatures", Journal of Physical Chemistry. A, Vol. 111, No. 26, pp. 5820-5827.

\begin{tabular}{|l|l|l|l|l|l|l|}
\hline & & & & & & SYN enol, crystal splitting \\
\hline $158 \mathrm{w}$ & $155 \mathrm{w}$ & $153 \mathrm{w}$ & $155 \mathrm{w}$ & $160 \mathrm{~m}, \mathrm{sh}$ & & $\begin{array}{l}\text { methyl group torsion } \\
\text { SYN enol (close to C-O-H) }\end{array}$ \\
\hline & & & $113 \mathrm{mw}, \mathrm{sh}$ & & & lattice vibration \\
\hline & $101 \mathrm{~s}$ & $101 \mathrm{vs}$ & $105 \mathrm{~s}$ & & lattice vibration \\
\hline & $86 \mathrm{~m}, \mathrm{br}$ & $89 \mathrm{~ms}$ & $90 \mathrm{mw}$ & & & lattice vibration \\
\hline & $71 \mathrm{~m}$ & $73 \mathrm{~ms}$ & $74 \mathrm{~m}$ & & & lattice vibration \\
\hline & $62 \mathrm{vvs}$ & $63 \mathrm{vvs}$ & $65 \mathrm{vvs}$ & & $\begin{array}{l}\text { coincidence of lattice vibration } \\
\text { and methyl group torsion } \\
\text { SYN enol (close to C }=\text { O) }\end{array}$ \\
\hline & & & & & lattice vibration \\
\hline & & $55 \mathrm{~ms}$ & $55 \mathrm{w}$ & & lattice vibration \\
\hline & $48 \mathrm{w}, \mathrm{sh}$ & $47 \mathrm{~m}$ & $48 \mathrm{w}$ & & lattice vibration \\
\hline & $39 \mathrm{w}$ & & $41 \mathrm{w}$ & & lattice vibration \\
\hline & $34 \mathrm{w}$ & $35 \mathrm{~m}$ & $35 \mathrm{w}$ & & keto lattice phonon \\
\hline
\end{tabular}

${ }^{a}$ The assignment of matrix bands is based on B1LYP/6-311G(d, p) calculations for SYN and TS2 enols from ref 7. Assignment of keto bands is based on B3LYP/6-31++G(d.p) calculations, ${ }^{40}$ this work. ${ }^{b}$ Abbreviations. v: very, s: strong, m: medium, w: weak, as: asymmetric, sh: shoulder, br: broad.

Generally, there are no bands corresponding to the keto isomer in the spectrum of matrix-isolated acac, but there is a superposition of weaker and broader bands onto stronger and narrower bands falling at the same wavenumber (see Figure 3); such is the case of a weak band at $1687 \mathrm{~cm}^{-1}$ underlying the stronger one at $1629 \mathrm{~cm}^{-1}$. We assign the band at $1687 \mathrm{~cm}^{-1}$ as a quasiaromatic carbonyl stretching band in the symmetric TS2 enol, and the band at $1629 \mathrm{~cm}^{-1}$ is assigned to the SYN enol. The shoulder at $1617 \mathrm{~cm}^{-1}$ is assigned as the TS2 enol band, and the strong band at $1602 \mathrm{~cm}^{-1}$ is assigned as belonging to the SYN enol. All 39 normal modes both for SYN and TS2 enols are active in Raman and infrared. Coussan, ${ }^{29}$ Nagashima, $^{30}$ and Chiavassa ${ }^{36}$ recorded infrared spectra of matrix-isolated acac. Nagashima's values for the argon matrix agree rather well with our reported values, and we could provide bands below $500 \mathrm{~cm}^{-1}$, neither of which were reported previously.

Matanović and Došlić ${ }^{7}$ calculated the $\mathrm{CH}$ stretching vibration of the methyne hydrogen of SYN enol at $3101 \mathrm{~cm}^{-1}$, higher than the corresponding mode in TS2 enol at $3098 \mathrm{~cm}^{-1}$ (at the anharmonic B1LYP/6-311G(d, p) level of theory). We observed two bands in the Raman matrix spectrum of acac, one at $3113 \mathrm{~cm}^{-1}$ and the other at $3082 \mathrm{~cm}^{-1}$. The methyne stretching band was assigned to the band at $3008 \mathrm{~cm}^{-1}$ in methylpropene, $\frac{41}{2}$ to the $3101 \mathrm{~cm}^{-1}$ band in butadiene, $\frac{42}{2}$ while in malonaldehyde, it was assigned to the band at $2848 \mathrm{~cm}^{-143}$ or reassigned to the $3060 \mathrm{~cm}^{-}$ ${ }^{1}$ band. $^{44}$ In acetylacetone, we assign the methyne $\mathrm{CH}$ stretching frequency of the SYN enol to the $3082 \mathrm{~cm}^{-1}$ band. The band at $3113 \mathrm{~cm}^{-1}$ could be a combination of the $1629 \mathrm{~cm}^{-1}$ band of the SYN enol and the asymmetric methyl bending at $1464 \mathrm{~cm}^{-1}$ of the same conformer.

Other bands involving the methyne group that are sensitive to the enol state are, according to ref 7, in-plane $\mathrm{CH}$ deformation predicted to be at $1183 \mathrm{~cm}^{-1}$ for SYN enol and at $1178 \mathrm{~cm}^{-1}$ for TS2 enol and out-of-plane $\mathrm{CH}$ deformation predicted to lie at $766 \mathrm{~cm}^{-1}$ for SYN isomer and at 758 
$\mathrm{cm}^{-1}$ for TS2 enol. We observed a shoulder at $1184 \mathrm{~cm}^{-1}$, a medium band at $1175 \mathrm{~cm}^{-1}$, and weak bands at 786 and $774 \mathrm{~cm}^{-1}$.

Upon careful inspection of the spectrum for the $\mathrm{O}-\mathrm{H}$ stretching band, we could not confidently assign it. The weak band at $\sim 3500 \mathrm{~cm}^{-1}$ was also observed in a subsequent matrix-isolation experiment performed by us, but no band of acetylacetone was simultaneously observed. Therefore, the $3500 \mathrm{~cm}^{-1}$ band is most probably caused by remnants of methanol that was used for cleaning of the apparatus. Nagashima et al. ${ }^{23}$ also observed a weak band at $3500 \mathrm{~cm}^{-1}$ in infrared matrix-isolation experiments and assigned it to small amounts of water interacting with acetylacetone. The bands at 2855 and $2721 \mathrm{~cm}^{-1}$ were observed in liquid and in polycrystalline solid as well and can be assigned as combinations of the SYN enol bands $\left(1602+1250 \mathrm{~cm}^{-1}\right)$ and $\left(1296+1435 \mathrm{~cm}^{-1}\right)$. A weak band at $365 \mathrm{~cm}^{-1}$ is a ring bending mode of SYN enol involving oxygen atoms. ${ }^{35}$

In conclusion, besides the SYN enol, another conformer (TS2) of acac was present in the isolate, characterized by the bands at 1687 and $1617 \mathrm{~cm}^{-1}$ and broad weak bands at 1470,1200, 786, and $615 \mathrm{~cm}^{-1}$.

Raman Spectra of Polycrystalline Acetylacetone. Acac, which is liquid at room temperature, freezes at $229 \mathrm{~K}$ upon cooling and further exhibits a solid-solid phase transition at $217 \mathrm{~K}$ (Figure 4). Upon heating, these phase changes occur at the higher temperatures of 254 and $225 \mathrm{~K}$. The transition at higher temperature is the freezing/melting transition, while the lower one probably involves the freezing/melting of the keto domains, as suggested by Johnson et al. ${ }^{20} \mathrm{We}$ compared Raman spectra of samples obtained by rapid cooling (spectrum at the top of Figure 5) and spectra of the annealed sample (shown at the bottom of Figure 5). The annealing procedure consisted of freezing the liquid at $230 \mathrm{~K}$, heating it to $240 \mathrm{~K}$, keeping it at that temperature for several hours (sometimes overnight), and then cooling down the sample to $10 \mathrm{~K}$. There were no bands at 1711 and $1700 \mathrm{~cm}^{-1}$ corresponding to $\mathrm{C}=\mathrm{O}$ stretching vibrations in keto isomers in the annealed samples (spectrum at the bottom of Figure 5). Other bands corresponding to keto acac in the rapidly cooled sample are the $975 \mathrm{~cm}^{-1}$ band (attributed to skeletal $\mathrm{C}-\mathrm{C}$ stretching), the $624 \mathrm{~cm}^{-1}$ band $\left(\mathrm{C}-\mathrm{CH}_{2}-\mathrm{C}\right.$ bending), and the $534 \mathrm{~cm}^{-1}$ band $(\mathrm{C}=\mathrm{O}$ in-plane bending). The positions of all observed bands are listed in Table 1 of the Supporting Material. The crystal structure of acetylacetone was determined at 210 and $110 \mathrm{~K}$ by Boese et al. ${ }^{19}$ It is Pnma with four molecules per unit cell and molecular site symmetry $C_{2 v}$. The number of expected optical phonons $\Gamma_{\text {opt ph }}=$ $3 \mathrm{~A}_{\mathrm{g}} \oplus_{3 \mathrm{~B}_{1 \mathrm{~g}}} \oplus_{3 \mathrm{~B}_{2 \mathrm{~g}}} \oplus_{3 \mathrm{~B}_{3 \mathrm{~g}}} \oplus_{3 \mathrm{~A}_{\mathrm{u}}} \oplus_{2} \mathrm{~B}_{1 \mathrm{u}} \oplus_{2 \mathrm{~B}_{2 \mathrm{u}}} \oplus_{2} \mathrm{~B}_{3 \mathrm{u}}$. All 12 gerade phonons are Raman active, and 6 phonons of $B_{1 u}, B_{2 u}$, and $B_{3 u}$ symmetry are infrared active. Nine low-frequency bands in the Raman spectrum of polycrystalline enol acac were assigned as lattice vibrations at $113,105,90,74,65,55,48,41$, and $35 \mathrm{~cm}^{-1}$. Phonon spectra of the annealed sample and of the sample that was rapidly cooled differ in the ratio of intensities of the 65 and $105 \mathrm{~cm}^{-1}$ phonon bands and in the appearance of the weak band at $27 \mathrm{~cm}^{-1}$ in the spectrum of rapidly cooled sample. Since we did not observe this band in the spectrum of annealed acac, it was assigned to a phonon from crystalline domains containing keto tautomers. 
Mohaček-Grošev, V., Furić, K., Ivanković, H. (2007), "Luminescence and Raman Spectra of Acetylacetone at Low Temperatures", Journal of Physical Chemistry. A, Vol. 111, No. 26, pp. 5820-5827.

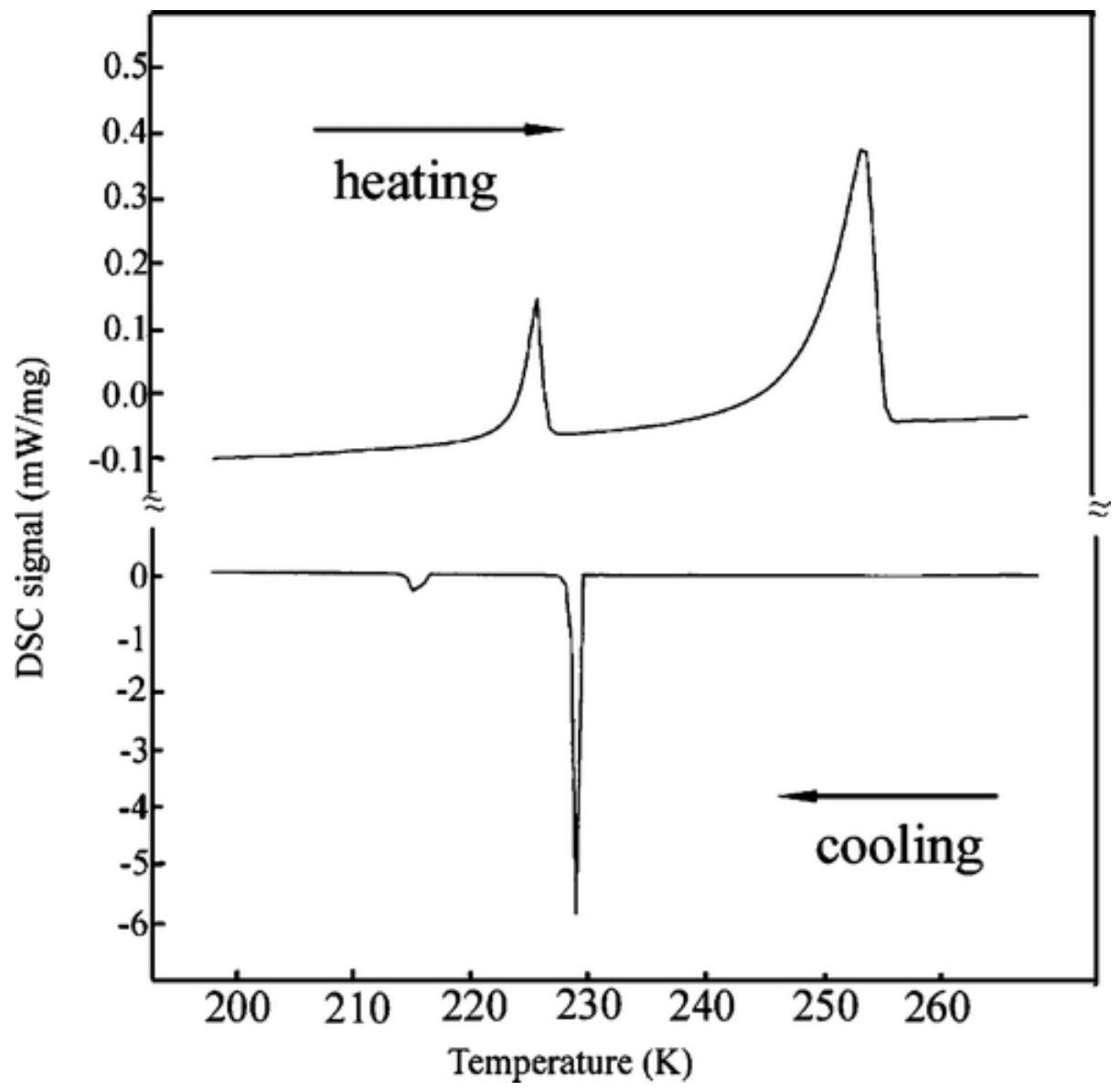

Fig 4 Differential scanning calorimetric signal of acetylacetone. The heating rate was $5 \mathrm{~K} / \mathrm{min}$, and the cooling rate was 5 $\mathrm{K} / \mathrm{min}$. 


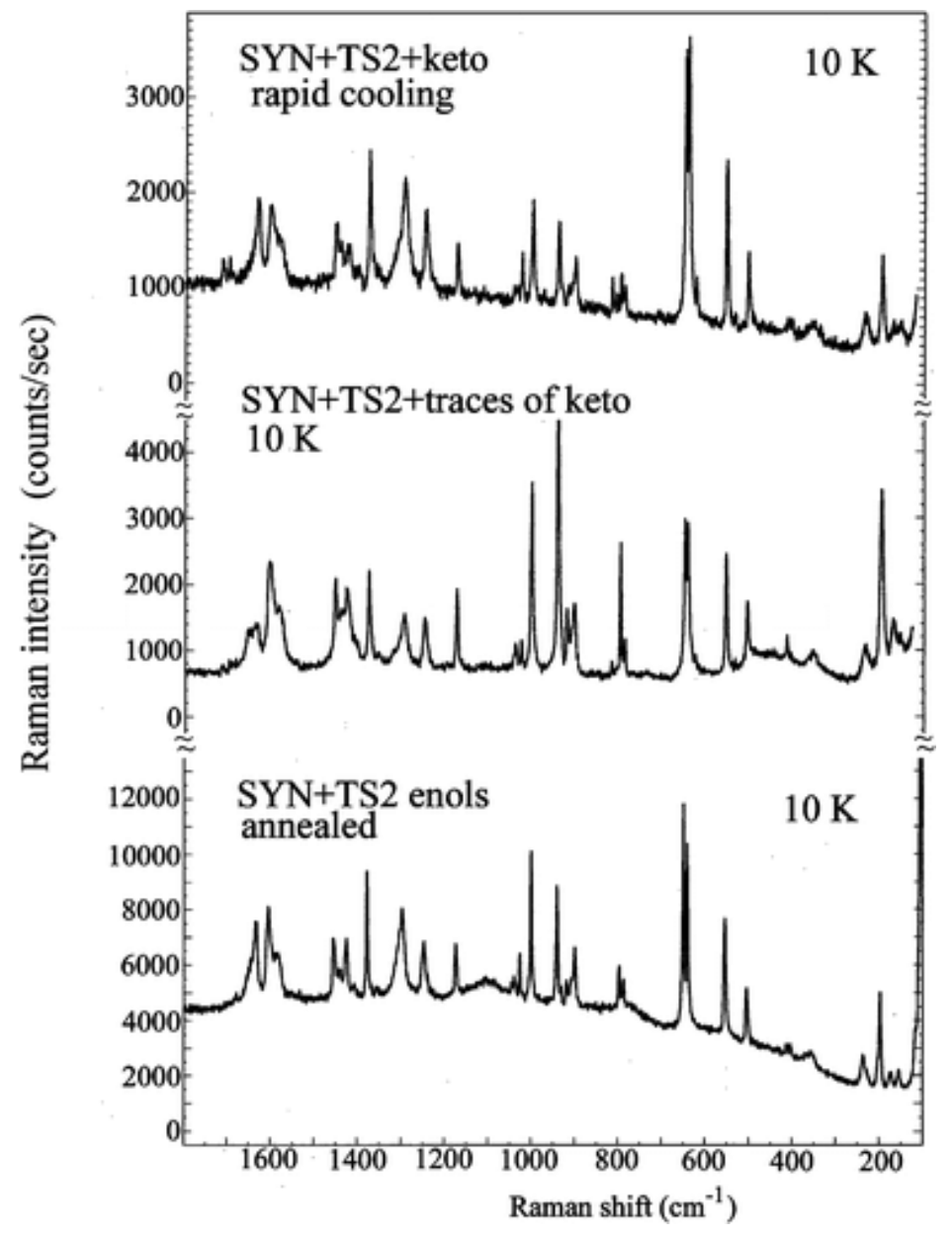

Fig 5 Low-temperature Raman spectra of polycrystalline acetylacetone at $10 \mathrm{~K}$ obtained when the sample was cooled rapidly from room temperature to $10 \mathrm{~K}$ (spectrum at the top), when the sample was cooled to $185 \mathrm{~K}$, heated above the solid-solid phase transition temperature to $230 \mathrm{~K}$, and then cooled to $10 \mathrm{~K}$ (middle spectrum), and for the annealed sample (spectrum at the bottom) in the $100-1800 \mathrm{~cm}^{-1}$ interval.

Among internal vibrations of acac, the lowest frequency modes are expected to be methyl torsional modes. Johnson et al. ${ }^{20}$ measured methyl torsional $0 \rightarrow 1$ transitions at 146.4 and 61.6 $\mathrm{cm}^{-1}$ in pure enolic polycrystalline acac and attributed the higher transition to the $\mathrm{CH}_{3}$ group closer to $\mathrm{C}-\mathrm{OH}$, while the lower transition proceeds between states of the methyl group proximal to $\mathrm{C}=\mathrm{O}$. In Raman spectra of annealed crystalline acac, the weak band at $155 \mathrm{~cm}^{-1}$ is assigned as the first torsional transition of methyl groups attached to $\mathrm{C}-\mathrm{OH}$ in SYN enol form of acetylacetone molecules. The band observed at $192 \mathrm{~cm}^{-1}$ in the matrix (Figure 3), corresponding to a mixed mode of out-of-plane ring bending and methyl torsion in SYN enol, splits in the spectrum of the annealed sample into two bands at 174 and $197 \mathrm{~cm}^{-1}$. In a similar manner, the band observed at $225 \mathrm{~cm}^{-1}$ in the matrix splits into bands at 203 and $228 \mathrm{~cm}^{-1}$ in the spectrum of the annealed sample at $10 \mathrm{~K}$.

Very broad bands of medium and strong intensity accompanied all Raman spectra and are discussed in the next section. The intensity distribution among the internal modes depends on the 
cooling procedure and the amount of enol conformer produced. It is often possible to observe the situation where, at $10 \mathrm{~K}$, the band at $1296 \mathrm{~cm}^{-1}$ is stronger than the band at $1605 \mathrm{~cm}^{-1}$ (Figure 5, spectrum at the top), while in another cooling, again at $10 \mathrm{~K}$, the ratio is reversed (Figure 5, spectrum in the middle).

Tayyari and Milani-Nejad ${ }^{35}$ gave a thorough assignment of the SYN enol vibrations, providing also bands from the solid. They reported two bands; the one at $1600 \mathrm{~cm}^{-1}$ was attributed to TS2 and the band at $1630 \mathrm{~cm}^{-1}$ to the SYN conformer, while they considered the band at $1575 \mathrm{~cm}^{-1}$ to be common to both SYN and TS2. Raman spectra in the carbonyl stretching region (1500-1800 $\mathrm{cm}^{-1}$ ) of polycrystalline acetylacetone and matrix-isolated acac are compared in Figure 6. Whereas at $85 \mathrm{~K}$ there is only one band at $1630 \mathrm{~cm}^{-1}$ in the polycrystalline annealed sample (spectrum at the top), at $10 \mathrm{~K}$, there is also a shoulder at $1652 \mathrm{~cm}^{-1}$ (spectrum in the middle), besides the other two bands at 1600 and $1585 \mathrm{~cm}^{-1}$. All of these bands are attributed to two internal SYN enol modes, which split into four modes in the crystal (see Table 1 for mode description).

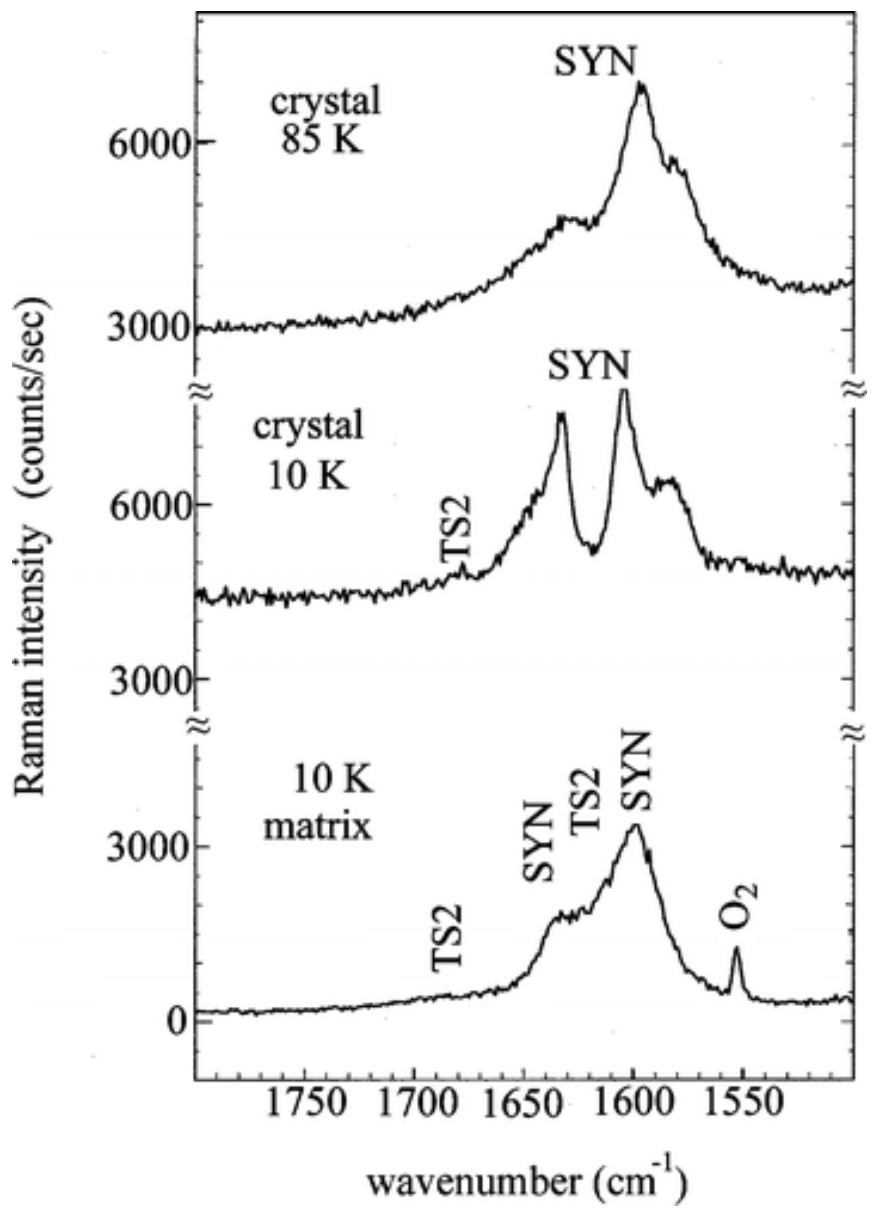

Fig 6 Comparison of Raman spectra of annealed polycrystalline acetylacetone at $85 \mathrm{~K}$ (spectrum at the top), at $10 \mathrm{~K}$ (middle spectrum), and with the spectrum of matrix-isolated acetylacetone at $10 \mathrm{~K}$ (spectrum at the bottom) $\left(1500-1800 \mathrm{~cm}^{-1}\right)$. Bands in the crystal belong to SYN enol, except a very weak band at $1683 \mathrm{~cm}^{-1}$ observed at $10 \mathrm{~K}$ and attributed to TS2 enol. 
Luminescence in Polycrystalline Acetylacetone. Luminescence bands are reported to appear together with Raman spectra of organic solutions ${ }^{45}$ in supraconductors ${ }^{46}$ and conjugated polymers. ${ }^{47}$ Usually, vibrational spectroscopists attribute the term luminescence to bands which appear in Raman spectra at different wavenumbers when different laser lines are used for excitation (their Raman shift varies) but are at the same absolute wavenumbers. Figure 7 shows the temperature-dependent Raman spectra of acac that were obtained when the green or blue laser line served as the excitation source. There are more bands when the blue line is used, and their band centers shift a little.
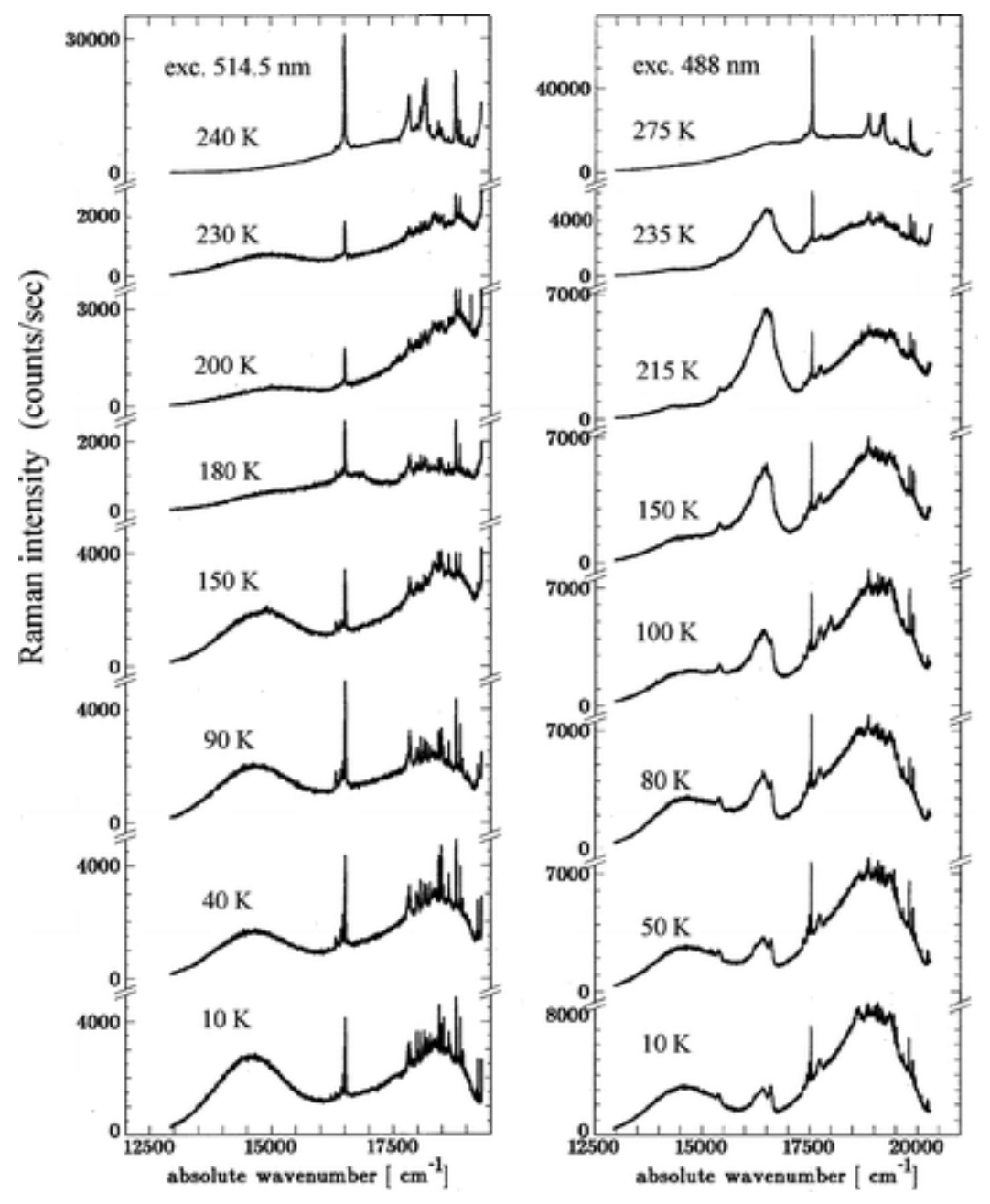

Fig 7 Temperature-dependent Raman spectra of acetylacetone displaying strong broad luminescence bands corresponding to frozen relaxation from higher energy isomers (see text). The excitation wavelengths were 514.5 $\mathrm{nm}\left(19436 \mathrm{~cm}^{-1}\right)$ and $488 \mathrm{~nm}\left(20458 \mathrm{~cm}^{-1}\right)$.

In the literature, ${ }^{27-34}$ there are several studies reporting on the UV photoisomerization of acetylacetone and of experiments performed using infrared radiation for conversions of one matrix-trapped isomer into the other. Here, we report photoisomerization that is going on in the visible part of the spectrum when the sample is solid at low temperature. The fact that the acac is 
Mohaček-Grošev, V., Furić, K., Ivanković, H. (2007), "Luminescence and Raman Spectra of Acetylacetone at Low Temperatures", Journal of Physical Chemistry. A, Vol. 111, No. 26, pp. 5820-5827.

solid at low temperature has two important consequences. First, if the sample is liquid, no absorption in the 2.2-2.5 eV interval can take place because the electronic states of molecules in liquid resemble those of free molecules, and in that energy interval, only the triplet $\mathrm{T}_{2}$ state is predicted to exist (or a series of triple states for different isomers). ${ }^{8,29-31} \mathrm{We}$ also recorded some UV-vis absorbance spectra of liquid acac, and there were no absorption bands in the 450-550 $\mathrm{nm}$ interval for liquid. Second, photons cannot be emitted if molecules make transitions from pure triplet states to the ground singlet state (spin zero); therefore, the electronic states to which acac molecules are excited and from which they decay into the ground state must have partial singlet character in the crystal. The broad bands that we report in Figure 7 (the laser line is green, $514.5 \mathrm{~nm}$, energy $2.41 \mathrm{eV}$ ) are not at the same wavenumbers as those which appear when the blue laser line (at $488.8 \mathrm{~nm}$, energy $2.53 \mathrm{eV}$ ) is used. The assignment of the band centers given in Table 2 is approximate because we compared the position of the band centers with the predicted energy difference for each isomer $E_{\text {laser }}-E_{\text {isomer. }}^{8,10,30}$

Table 2 Observed Broad Bands Underlying Low-Temperature Raman Spectra of Acetylacetone

\begin{tabular}{|c|c|c|c|c|c|c|c|}
\hline \multicolumn{4}{|c|}{ excitation $\lambda_{0}=514.5 \mathrm{~nm} v \sim_{0}=19436 \mathrm{~cm}^{-1}$} & \multicolumn{4}{|c|}{ Excitation $\lambda_{0}=488.8 \mathrm{~nm} v \sim_{0}=20458 \mathrm{~cm}^{-1}$} \\
\hline \begin{tabular}{|l|l|}
$T$ \\
$(\mathrm{~K})$
\end{tabular} & $\begin{array}{l}V \approx R \\
\left(\mathrm{~cm}^{-1}\right)\end{array}$ & $\begin{array}{l}v \sim_{0}-v \approx_{R} \\
\left(\mathrm{~cm}^{-1}\right)\end{array}$ & $\begin{array}{l}\text { AcAc isomer giving origin } \\
\text { to the band }\end{array}$ & $\begin{array}{l}T \\
(\mathrm{~K})\end{array}$ & $\begin{array}{l}V \approx R \\
\left(\mathrm{~cm}^{-1}\right)\end{array}$ & $\begin{array}{l}\nu \sim_{0}-v \sim_{R} \\
\left(\mathrm{~cm}^{-1}\right)\end{array}$ & $\begin{array}{l}\text { AcAc isomer giving origin } \\
\text { to the band }\end{array}$ \\
\hline \multirow[t]{2}{*}{230} & 4635 & 14800 & CTC,CTT & 235 & 6208 & 14250 & CCT \\
\hline & 785 & 18650 & TS1 enol + keto & & 3958 & 16500 & СТС,CТT,TCC \\
\hline \multirow{2}{*}{200} & 4435 & 15000 & СТC,CTT & & 1458 & 19000 & TS1 enol+keto \\
\hline & 835 & 18600 & TS1 enol + keto & 215 & 6158 & 14300 & CCT \\
\hline \multirow{3}{*}{180} & 4200 & 15236 & CTC,CTT & & 3958 & 16500 & CTC,CTT,TCC \\
\hline & 2735 & 16700 & transition state & & 1490 & 18968 & TS1 enol+ keto \\
\hline & 1035 & 18400 & TS1 enol + keto & 150 & 5758 & 14700 & CCT \\
\hline \multirow[t]{2}{*}{150} & 4635 & 14800 & CTC,CTT,TCC & & 4008 & 16450 & CTC,CTT,TCC \\
\hline & 985 & 18450 & TS1 enol + keto & & 1458 & 19000 & TS1 enol+ keto \\
\hline \multirow[t]{3}{*}{90} & 4735 & 14700 & CTC,CTT,TCC & 100 & 5758 & 14700 & CCT \\
\hline & 1085 & 18350 & TS1 enol + keto & & 4008 & 16450 & CTC,CTT,TCC \\
\hline & & & & & 1458 & 19000 & TS1 enol+keto \\
\hline \multirow[t]{3}{*}{40} & 4735 & 14700 & СТC,CTT,TCC & 80 & 5758 & 14700 & $\mathrm{CCT}$ \\
\hline & 1035 & 18400 & TS1 enol + keto & & 4008 & 16450 & СТC,СТT,ТCC \\
\hline & & & & & 1558 & 18900 & TS1 enol+ keto \\
\hline \multirow[t]{6}{*}{10} & 4835 & 14600 & СТС,СТT,ТCC & 50 & 5858 & 14600 & CCT \\
\hline & 1085 & 18350 & TS1 enol + keto & & 4058 & 16400 & СТC,CTT,TCC \\
\hline & & & & & 1558 & 18900 & TS1 enol+ keto \\
\hline & & & & 10 & 5858 & 14600 & CT \\
\hline & & & & & 4058 & 16400 & CTC,CTT,TCC \\
\hline & & & & & 1558 & 18900 & TS1 enol+keto \\
\hline
\end{tabular}




\section{Discussion}

Among systems displaying keto-enol tautomerism, such as 1-hydroxyanthraquinone ${ }^{48}$ or 2-(2‘hydroxyphenyl)benzoxazole, ${ }^{49}$ enol and keto singlet and triplet states are close in energy, and upon excitation, a number of relaxation pathways are possible. A similar situation is found in acetylacetone, whose excited electronic states were studied by Chen et al., ${ }^{8}$ Nakanishi et al., ${ }^{27}$ Coussan et al., ${ }^{28}$ Nagashima et al., ${ }^{30}$ and Upadhyaya et al., ${ }^{31}$ among others. The strong UV band appearing at $266 \mathrm{~nm}$ in the absorption spectra corresponds to the $S_{0} \rightarrow S_{2}$ transition. The $S_{2}$ state decays into lower $\mathrm{S}_{1}, \mathrm{~T}_{2}$, and $\mathrm{T}_{1}$ states, which decay further into ground states of different acac isomers. $^{27-34}$ The notation used to describe the isomers consists of three capital letters CCC, CTC, an so forth. The first letter refers to the conformation with respect to rotation around the carbon-carbon single bond in the ring, the second letter describes conformation with respect to rotation around the double carbon bond, and the third letter refers to conformation with respect to rotation around the carbon-hydroxyl oxygen bond. Absorption selection rules for photons forbid singlet-to-triplet transitions, but it is known that, in the solid state, the excited states are not pure singlet or triplet states. ${ }^{47}$ Figure 8 shows an energy level diagram depicting data from Matanović and Došlić, ${ }^{10}$ Nagashima et al., ${ }^{30}$ and Chen et al. ${ }^{8}$ In the interest of clarity, not all transition triplet states listed in ref 8 are shown. One can see that, in the region of our green laser excitation $\left(19436 \mathrm{~cm}^{-1}\right)$, the enol triplet state of the free acac molecule $\mathrm{E}\left(\mathrm{T}_{1}\right)$ is predicted at $19845 \mathrm{~cm}^{-1},{ }^{8}$ while around the energy of the blue argon ion laser line $\left(20458 \mathrm{~cm}^{-1}\right)$, three states are predicted at 20405, $\left(\mathrm{CTT}\left(\mathrm{T}_{1}\right)\right), 20440\left(\mathrm{CCT}\left(\mathrm{T}_{1}\right)\right)$, and $20545 \mathrm{~cm}^{-1}\left(\mathrm{TCC}\left(\mathrm{T}_{1}\right)\right) .{ }^{8}$ Because electronic states in the solid have bandwidths on the order of $1600 \mathrm{~cm}^{-1},{ }^{50}$ these states are all accessible with our laser excitation. In Table 2, we give the tentative assignment of the broad bands observed in polycrystalline acac shown in Figure 7. Three isomers have their energy approximately 4000-5000 $\mathrm{cm}^{-1}$ above the ground state of the CCC isomer. They are CTC, CTT, and TCC isomers, and the bands that correspond to them occur in the $14200-14800 \mathrm{~cm}^{-1}$ interval when the green laser line is used $(514.5 \mathrm{~nm})$ and in the $16400-16600 \mathrm{~cm}^{-1}$ interval when the $488 \mathrm{~nm}$ excitation is used. The huge intensity difference observed in the case of the blue line is caused by a preresonance condition; the energy of the excited mixed singlet-triplet bands is dependent on temperature in such a manner that, at $215 \mathrm{~K}$, the laser photons are closer in energy to the excited singlet/triplet band of the CTC, CTT, and TCC isomers. At $100 \mathrm{~K}$ and below, the excited singlet/triplet states of the keto isomer and TS1 enol are closer to the energy of incoming photons. Upon excitation, molecules relax to the ground isomer states, whose populations reflect this. 


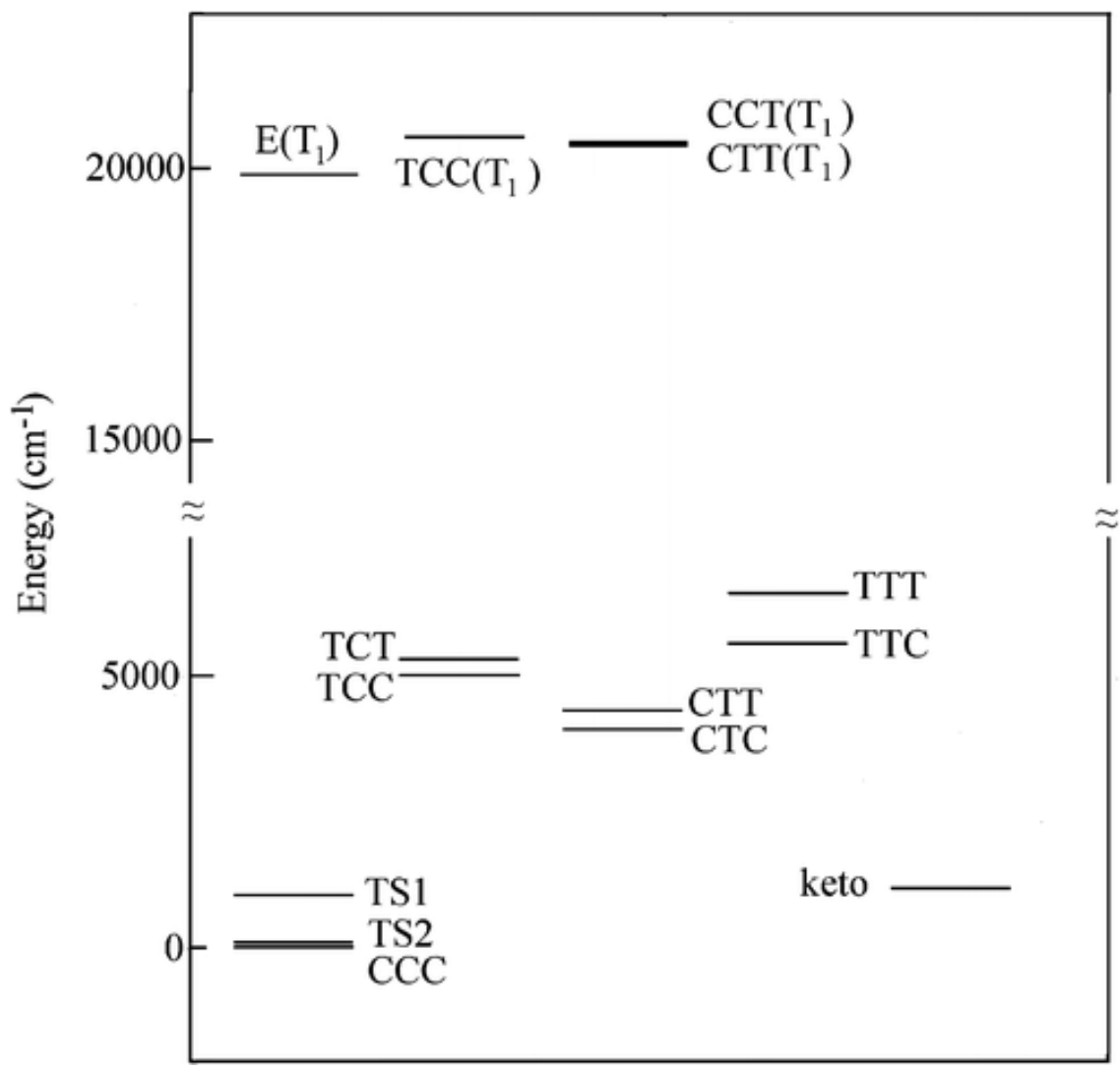

Fig 8 Energy level diagram of acetylacetone ground and excited states based on predicted values for TS1 and TS2, ${ }^{10} \mathrm{E}\left(\mathrm{T}_{1}\right), \mathrm{TCC}\left(\mathrm{T}_{1}\right), \mathrm{CCT}\left(\mathrm{T}_{1}\right)$, and CTT $\left(\mathrm{T}_{1}\right)^{8}$ and the rest from ref 30 . Not all states are shown; please see references mentioned for a more complete list.

In matrix-isolation experiments, no luminescence bands were observed because of the weak interactions between molecules. In polycrystalline solid, on the other hand, the intermolecular interaction caused changes in the nature of the excited electronic states of acac from the pure triplet to mixtures of singlet and triplet states.

\section{Conclusion}

Light-scattering experiments on acetylacetone at low temperatures display a number of strong broad bands appearing beneath the Raman spectra of the solid. These results are interpreted as transitions from molecules excited to higher states to various isomers in the ground electronic state. Laser photons of energies 19436 and $20458 \mathrm{~cm}^{-1}$ excite acac in the region where a number of excited triplet states are predicted for the free acetylacetone molecule. Since singlet-to-triplet photon absorption transitions are forbidden, we conclude that states existing in solid acac have mixed singlet/triplet character. Their decay results in population of different isomer states, which are not vibrationally resolved, except for the lowest isomers, SYN enol, the TS2 transition state, and the keto form, which can be detected in solid Raman spectra. 
The molecular conformation of matrix-isolated acetylacetone is dominantly SYN enol. Nevertheless, bands corresponding to the enol conformer, with symmetrically placed methyl groups (TS2 enol), are also observed.

\section{Acknowledgment}

This work was made possible by the Grants 0098019, 0098022, and 0125019 of the Ministry of Science, Technology and Sport of the Republic of Croatia. Thanks are due to Mr. David M. Smith for kindly reading the manuscript.

Supporting Information Avaliable

Observed Raman and infrared bands, calculated unscaled frequencies, and Raman spectra. This material is available free of charge via the Internet at http://pubs.acs.org.

\section{References}

(1) Emsley, J. Struct. Bonding 1984, 57, 147.

(2) Imao, T.; Noma, N.; Ito, S. J. Sol-Gel Sci. Technol. 2006, 38, 197.

(3) Tsaryuk, V.; Zolin, V.; Legendziewicz, J.; Szostak, R.; Sokolnicki, J. Spectrochim. Acta, Part A 2005, 61, 185.

(4) Zhang, R.-J.; Yang, K.-Z.; Yu, A.-C.; Zhao, X.-S. Thin Solid Films 2000, 363, 275.

(5) Cohen, B.; Weiss, S. J. Phys. Chem. 1984, 88, 3159.

(6) Emsley, J.; Freeman, N. J. J. Mol. Struct. 1987, 161, 193.

(7) Matanovic', I.; Dos`lic', N. Int. J. Quantum Chem. 2006, 106, 1367.

(8) Chen, X.-B.; Fang, W.-H.; Phillips, D. L. J. Phys. Chem. A 2006, 110, 4434.

(9) Cabral do Couto, P.; Costa Cabral, B. J.; Martinho Simoes, J. A. Chem. Phys. Lett. 2006, 419, 486.

(10) Matanovic', I.; Dos`lic', N. J. Phys. Chem. A 2005, 109, 4185.

(11) Campomanes, P.; Menendez, M. I.; Sordo, T. L. J. Mol. Struct.: THEOCHEM 2005, 713, 59.

(12) Matanovic', I.; Dos`lic', N.; Mihalic', Z. Chem. Phys. 2004, 306, 201.

(13) Szilnev, V. V.; Lapshina, S. B.; Girichev, G. V. J. Struct. Chem. 2002, 43, 47.

(14) Mavri, J.; Grdadolnik, J. J. Phys. Chem. A 2001, 105, 2039.

(15) Mavri, J.; Grdadolnik, J. J. Phys. Chem. A 2001, 105, 2045.

(16) Sharafeddin, O. A.; Hinsen, K.; Carrington, T., Jr.; Roux, B. J. Comput. Chem. 1997, 18, 1760.

(17) Dannenberg, J. J.; Rios, R. J. Phys. Chem. A 1994, 98, 6714.

(18) Gromak, V. V. J. Mol. Struct.: THEOCHEM 2005, 726, 213.

(19) Boese, R.; Antipin, M. Yu.; Bla“ser, D.; Lyssenko, K. A. J. Phys. Chem. B 1998, 102, 8654. 
Mohaček-Grošev, V., Furić, K., Ivanković, H. (2007), "Luminescence and Raman Spectra of Acetylacetone at Low Temperatures", Journal of Physical Chemistry. A, Vol. 111, No. 26, pp. 5820-5827.

(20) Johnson, M. R.; Jones, N. H.; Geis, A.; Horsewill, A. J.; Trommsdorff, H. P. J. Chem. Phys. 2002, 116, 5694.

(21) Caminati, W.; Grabow, J.-U. J. Am. Chem. Soc. 2006, 128, 854.

(22) Lowrey, A. H.; George, C.; D’Antonio, P.; Karle, J. J. Am. Chem. Soc. 1971, 93, 6399.

(23) Ijima, K.; Ohnogi, A.; Shibata, S. J. Mol. Struct. 1987, 156, 111.

(24) Srinivasan, R.; Feenstra, J.-S.; Park, S. T.; Xu, S.; Zewail, A. H. J. Am. Chem. Soc. 2004, $126,2266$.

(25) Camerman, A.; Mastropaolo, D.; Camerman, N. J. Am. Chem. Soc. 1983, 105, 1584.

(26) Veierov, D.; Bercovici, T.; Fischer, E.; Mazur, Y.; Yogev, A. J. Am. Chem. Soc. 1973, 95, 8173.

(27) Nakanishi, H.; Morita, H.; Nagakura, S. Bull. Chem. Soc. Jpn. 1977, 50, 2255.

(28) Coussan, S.; Ferro, Y.; Trivella, A.; Rajzmann, M.; Roubin, P.; Wieczorek, R.; Manca, C.;

Piecuch, P.; Kowalski, K.; Wloch, M.; Kucharski, S. A.; Musial, M. J. Phys. Chem. A 2006, $110,3920$.

(29) Coussan, S.; Manca, C.; Ferro, Y.; Roubin, P. Chem. Phys. Lett. 2003, 370, 118.

(30) Nagashima, N.; Kudoh, S.; Takayanagi, M.; Nakata, M. J. Phys. Chem. A 2001, 105, 10832.

(31) Upadhyaya, H. P.; Kumar, A.; Naik, P. D. J. Chem. Phys. 2003, 118, 2590.

(32) Minoura, Y.; Nagashima, N.; Kudoh, S.; Nakata, M. J. Phys. Chem. A 2004, 108, 2353.

(33) Walzl, K. N.; Xavier, I. M., Jr.; Kuppermann, A. J. Chem. Phys. 1987, 86, 6701.

(34) Schweig, A.; Vermeer, H.; Weidner, U. Chem. Phys. Lett. 1974, 26, 229.

(35) Tayyari, S. F.; Milani-Nejad, F. Spectrochim. Acta, Part A 2000, 56, 2679.

(36) Chiavassa, T.; Verlaque, P.; Pizzala, L.; Roubin, P. Spectrochim. Acta, Part A 1994, 50, 343.

(37) Tayyari, S. F.; Zeegers-Huyskens, Th.; Wood, J. L. Spectrochim. Acta, Part A 1979, 35, 1265.

(38) Tayyari, S. F.; Zeegers-Huyskens, Th.; Wood, J. L. Spectrochim. Acta, Part A 1979, 35, 1289.

(39) Ogoshi, H.; Nakamoto, K. J. Chem. Phys. 1966, 45, 3113.

(40) Frisch, M. J.; Trucks, G. W.; Schlegel, H. B.; Scuseria, G. E.; Robb, M. A.; Cheeseman, J.

R.; Montgomery, J. A., Jr.; Vreven, T.; Kudin, K. N.; Burant, J. C.; Millam, J. M.; Iyengar, S.

S.; Tomasi, J.; Barone, V.; Mennucci, B.; Cossi, M.; Scalmani, G.; Rega, N.; Petersson, G. A.; Nakatsuji, H.; Hada, M.; Ehara, M.; Toyota, K.; Fukuda, R.; Hasegawa, J.; Ishida, M.;

Nakajima, T.; Honda, Y.; Kitao, O.; Nakai, H.; Klene, M.; Li, X.; Knox, J. E.; Hratchian, H. P.; Cross, J. B.; Bakken, V.; Adamo, C.; Jaramillo, J.; Gomperts, R.; Stratmann, R. E.;

Yazyev, O.; Austin, A. J.; Cammi, R.; Pomelli, C.; Ochterski, J. W.; Ayala, P. Y.; Morokuma, K.; Voth, G. A.; Salvador, P.; Dannenberg, J. J.; Zakrzewski, V. G.; Dapprich, S.; Daniels, A. D.; Strain, M. C.; Farkas, O.; Malick, D. K.; Rabuck, A. D.; Raghavachari, K.; Foresman, J. B.; Ortiz, J. V.; Cui, Q.; Baboul, A. G.; Clifford, S.; Cioslowski, J.; Stefanov, B. B.; Liu, G.; Liashenko, A.; Piskorz, P.; Komaromi, I.; Martin, R. L.; Fox, D. J.; Keith, T.; Al-Laham, M. 
A.; Peng, C. Y.; Nanayakkara, A.; Challacombe, M.; Gill, P. M. W.; Johnson, B.; Chen, W.; Wong, M. W.; Gonzalez, C.; Pople, J. A. Gaussian 03, revision C.02; Gaussian, Inc.:

Wallingford, CT, 2004 (41) Radiszewski, J. G.; Downing, J. W.; Gudipati, M. S.; Balaji, V.;

Thulstrup, E. W.; Michl, J. J. Am. Chem. Soc. 1996, 118, 10275.

(42) Wilson, E. B.; Smith, Z. J. Mol. Spectrosc. 1982, 94, 399.

(43) Wilson, E. B.; Smith, Z.; Duerst, R. Spectrochim. Acta, Part A 1983, 39, 1117.

(44) Tayyari, S. F.; Milani-Nejad, F. Spectrochim. Acta, Part A 1998, 54, 255.

(45) Nakamura, R.; Yamamoto, S.; Nakahara, J. J. Chem. Phys. 2002, 117, 238.

(46) Kuroe, H.; Kaneko, T.; Sekine, T.; Sarmago, R. V.; Koide, N.; Masuda, T.; Tsukada, I.;

Uchinokura, K. Physica B 2000, 284-288, 1643.

(47) Woo, H. S.; Graham, S. C.; Halliday, D. A.; Bradley, D. D. C.; Friend, R. H. Phys. ReV. B 1992, 46, 7379 .

(48) Cho, D. W.; Kim, S. H.; Yoon, M; Jeoung, S. C. Chem. Phys. Lett. 2004, 391, 314.

(49) Walla, P.; Nickel, B. Chem. Phys. 2005, 312, 177.

(50) Petelenz, P.; Slawik, M.; Yokoi, K.; Zgierski, M. Z. J. Chem. Phys. 1996, 105, 4427. 